\title{
Synergistic Effect of Nogo-Neutralizing Antibody IN-1 and Ciliary Neurotrophic Factor on Axonal Regeneration in Adult Rodent Visual Systems
}

\author{
QI CUI, ${ }^{1,2}$ KIN-SANG CHO, ${ }^{2,3}$ KWOK-FAI SO, ${ }^{2}$ and HENRY K. YIP
}

\begin{abstract}
The presence of Nogo axon regeneration inhibitory molecules in the central nervous system (CNS) and the counteracting effect of IN-1 antibodies have been widely reported. In this study, we examined the effect of IN-1-producing hybridoma cells on axon regeneration in adult rodent retinal ganglion cells (RGCs) after various types of optic nerve (ON) injury, evaluating therein whether ciliary neurotrophic factor (CNTF) potentiated the effect of IN-1. We found that application of IN-1 alone failed to enhance regeneration of intracranially or intraorbitally transected RGC axons in a peripheral nerve (PN) graft. IN-1 hybridoma cells also failed to significantly promote intraorbitally crushed ON axons to reenter the distal part of the ON. However, a combined application of IN-1 and CNTF had a synergistic effect in both intracranial PN and intraorbital ON crush paradigms. This study suggests that the action of IN-1 antibodies in promoting axon regeneration in the CNS could be more effective when coupled with other appropriate factors.
\end{abstract}

Key words: axon regeneration; ciliary neurotrophic factor; IN-1; Nogo; optic nerve injury; peripheral nerve graft

\section{INTRODUCTION}

$\mathbf{T}$ HE PRESENCE of various aXon regeneration inhibitory molecules (Nogo, MAG, and OMgp) in the myelin and oligodendrocytes of the central nervous system (CNS) has been well documented over the past 15 years (Caroni and Schwab, 1988; McKerracher et al., 1994; Mukhopadhyay et al., 1994; Kottis et al., 2002). Three different isoforms of Nogo have been cloned (Nogo-A, Nogo-B, and Nogo-C), with identification of two inhibitory domains (Nogo-66 and Amino-Nogo) in Nogo A (Chen et al., 2000; GrandPre et al., 2000; Fournier et al., 2001). The effect of IN-1 antibodies, which are raised in hybridoma cells and shown to block Nogo-A molecules, has been studied with some success in the CNS, particularly in the repair of adult spinal cord (Bregman et al., 1995; Z'Graggen et al., 1998).

Retinal ganglion cells (RGCs) in the mammalian visual system are of particular interest to neuroscientists conducting studies of axonal regeneration after CNS injury. The peripheral nerve (PN) bridging approach in visual system models has achieved success in promoting RGC axonal regeneration (Richardson et al., 1980; So and Aguayo, 1985). Recently, using this PN-grafting

\footnotetext{
${ }^{1}$ Laboratory for Neural Repair, Shantou University Medical College, Shantou, China.

${ }^{2}$ Department of Anatomy, Faculty of Medicine, University of Hong Kong, Hong Kong.

${ }^{3}$ Schepens Eye Research Institute Department of Ophthalmology, Harvard Medical School, Boston, Massachusetts.
} 
experimental paradigm, we showed that ciliary neurotrophic factor (CNTF) significantly increased axonal regeneration of axotomized RGCs in adult rodents (Cui et al., 1999; 2003; Cui and Harvey, 2000). Although RGC axonal outgrowth was enhanced by $\mathrm{IN}-1$ treatment in vitro (Bähr and Schwab, 1996) and in developing rats (Weible et al., 1994), little is known about the effect of IN-1 on the regeneration of RGC in adults. As Nogo has been shown to express in the optic nerve $(\mathrm{ON})$, ganglion cell layer of the retina, and PN (Hunt et al., 2002), we thought it would be interesting to see what effect IN1-producing hybridoma cells would have on adult rodent RGC axonal regeneration when applied along PN grafts. Because different sites of ON injury appear to have different effects on the extent of RGC loss and axon regeneration (You et al., 2000), a phenomenon probably owing to the presence of a differential amount of inhibitory molecules in ON stumps of different lengths, we used both intracranial (distal) and intraorbital (proximal) ON transection models in this study. We also used an intraorbital ON crush model to determine whether RGC axons could regenerate across the injury site into the distal part of the ON, a hostile CNS environment. As CNTF has been shown to promote RGC axon regeneration (Cui et al., 1999, 2003), and combined application of neurotrophin-3 and IN-1 antibody promotes long-distance axon regeneration in spinal cord (Schnell et al., 1994), in this study we used a combined approach of applying IN-1 hybridoma cells along the PN or ON and injecting CNTF into the eyes.

\section{MATERIALS AND METHODS}

Young adult (6-8 weeks old; Mesocricetus auratus) hamsters were used in the intracranial and intraorbital PN graft models, while Sprague-Dawley (SD) rats were used in the intraorbital ON crush model. All hamsters underwent $\mathrm{ON}$ transection, and a $1.5-\mathrm{cm}-$ long PN graft was attached to the ON stump. The rats all underwent intraorbital ON crush. The experimental procedures for these paradigms have been described elsewhere (Cui et al., 1999, 2003; Yin et al., 2003). All surgical procedures were carried out under Sagatal (sodium pentobarbitone, $60 \mathrm{mg} / \mathrm{kg}$ body wt) anesthesia in hamsters, and ketamine ( $65 \mathrm{mg} / \mathrm{kg}$ body wt) and Xylazine $(6.5 \mathrm{mg} / \mathrm{kg}$ body wt) anesthesia in rats.

\section{Intracranial PN Graft Experiments}

For intracranial ON transection, a small hole was drilled in the left frontal bone just rostral $(1.5 \mathrm{~mm})$ to the bregma. Neural tissue below the craniotomy was removed by aspiration to expose the left ON. A pair of small scissors was used to completely transect the ON (about $7 \mathrm{~mm}$ from the optic disc). A 1.5-cm-long segment of autologous peroneal branch of sciatic nerve was obtained from the left leg, guided into the cranial cavity, and apposed onto the proximal stump of the transected ON (Fig. 1A). The connection of the PN graft with the ON stump was maintained by packing the cavity with pieces of Gelfoam. This approach has been shown to maintain the PN-ON interface successfully (Lau et al., 1994). The remaining portion of the PN (distal part) was placed on top of the skull and secured to surrounding tissue using $6 / 0$ suture.

After the PN grafting procedure, animals were divided into six groups. Group $1(n=5)$, the control group, received horseradish peroxidase (HRP) antibodies-producing hybridoma cells contained in filter paper capsules (Ravioli). Group $2(n=23)$ received IN-1 hybridoma cells in Ravioli. Group $3(n=10)$ received direct application of IN-1 hybridoma cells soaked in Gelfoam and daily intraperitoneal (i.p.) injection of immunosuppressant cyclosporin-A (CsA) (1 mg/100 g/day) for 20 days. Group $4(n=5)$ received IN-1 hybridoma cells in Ravioli and intravitreal injections of CNTF. To apply CNTF intravitreally, a total of five injections $(1 \mu \mathrm{g} / \mu \mathrm{L} \times 5)$ in each animal were performed every 5 days, starting from the day of axotomy. Group $5(n=5)$ received HRP hybridoma cells in Ravioli and a PN segment $(2 \mathrm{~mm})$ in the eye. The final group $(n=4)$ received $\mathrm{IN}-1$ hybridoma cells in Ravioli and a PN segment $(2 \mathrm{~mm})$ in the eye.

The biological activity of the HRP- or IN-1-producing hybridoma cells was tested in vitro before use. After expanding the cells in modified ISCOVE's medium containing $10 \%$ fetal calf serum, $2 \mathrm{mM}$ L-glutamate, 100 $\mathrm{U} / \mathrm{mL}$ penicillin, $100 \mu \mathrm{g} / \mathrm{mL}$ streptomycin sulfate, and $50 \mu \mathrm{M} \beta$-mercaptoethanol, cells were washed and then centrifuged for $5 \mathrm{~min}$. The supernatant was discarded and the cells were resuspended in an appropriate concentration for injection into the Ravioli or direct application. The Ravioli holding the hybridoma cells was made of filter paper. A Ravioli containing either $10^{6} \mathrm{HRP}$ or $10^{6}$ IN-1 cells was implanted over the top of the intracranially transected ON. Another Ravioli containing $5 \times 10^{5}$ of the same cell type was also applied intraorbitally along the dura-opened ON (Fig. 1A) to maximize the effect of the antibody-producing cells. For the direct application of the cells in Group 3, $10^{6} \mathrm{IN}-1$ cells soaked in Gelfoam were applied into the cranial cavity on top of the transected ON and PN graft.

\section{Intraorbital PN Graft Experiments}

To axotomize the ON intraorbitally, the ON was accessed through the dorsal opening of the orbit after ex- 


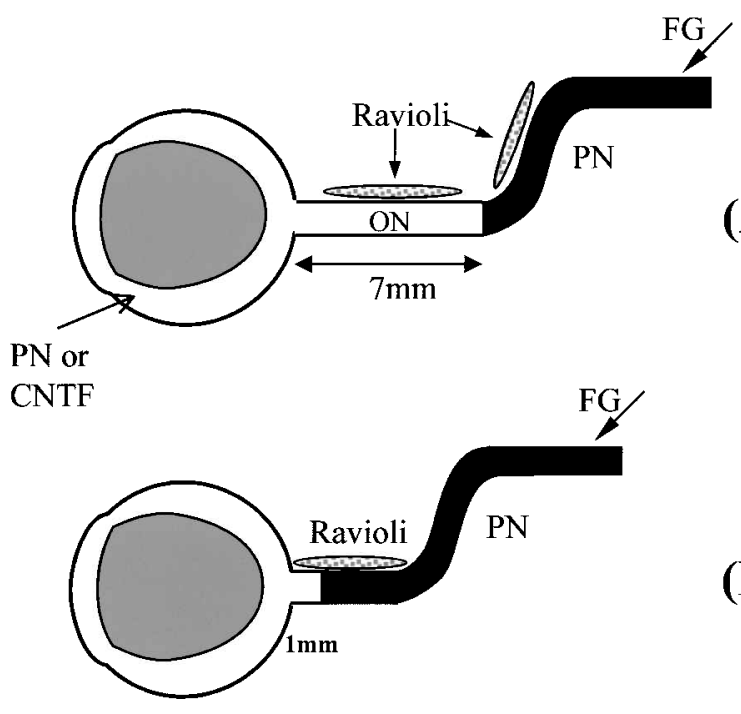

(A)

(B)

Saline or CNTF

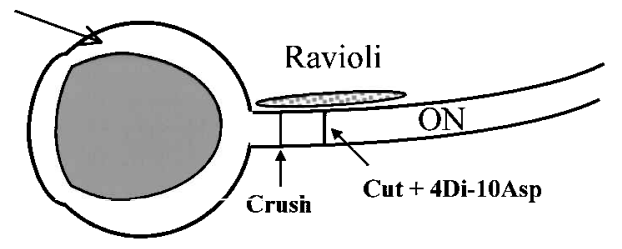

(C)

FIG. 1. Experimental paradigms in this study. (A) Intracranial ON axotomy and transplantation of a PN graft. Animals were treated with either HRP cells or IN-1 cells, in Ravioli or applied directly with i.p injections of CsA. In some animals, intravitreal injections of CNTF or insertion of a PN segment were performed. (B) Intraorbital ON axotomy and transplantation of a PN graft. Animals were treated with HRP cells or IN-1 cells in Ravioli. (C) Intraorbital ON crush model. Animals were treated with IN1 cells in Ravioli, CNTF in eye, or both treatments combined. Saline-injected animals served as controls.

cision of the superior extraocular muscles. The dural sheath of the ON was then opened with a $27 \frac{1}{2}$-gauge needle, and a pair of small scissors was used to completely transect the $\mathrm{ON}$ inside the dura at a distance of about $1.5 \mathrm{~mm}$ from the optic disc. A $1.5-\mathrm{cm}$ segment of peroneal nerve was sutured (10/0) onto the axotomized ON. The distal part of the PN graft was secured onto the surrounding tissue on the skull. The animals were divided into two groups (Table 1). Group 1 received $10^{6} \mathrm{HRP}$ cells, and group 2 received $10^{6} \mathrm{IN}-1$ cells intraorbitally, both by means of a Ravioli application along the opened ON (Fig. 1B).

\section{Intraorbital ON Crush Experiments}

To further test the effect of IN-1 on axonal regeneration of RGCs, an intraorbital ON crush injury was per- formed in adult rats. The ON was accessed through the same approach described above. A large proportion of the ON dural sheath was then opened with a $271 / 2$ gauge needle for better penetration of the IN-1 antibodies. A pair of fine forceps was used to completely crush the $\mathrm{ON}$ inside the dura at a distance of about $1.5 \mathrm{~mm}$ from the optic disc. Four groups of animals were studied in this model. Group $1(n=4)$ received intravitreal injections of saline (Fig. 1C). Group $2(n=5)$ received intravitreal injections of CNTF. Group $3(n=5)$ received IN-1 cells in Ravioli. Group $4(n=5)$ received IN-1 cells in Ravioli and intravitreal injections of CNTF (Fig. 1C). As we had previously found that CNTF significantly enhanced the RGC axon regeneration of rodents in a dosedependent manner (Cui et al., 1999), four injections of CNTF ( $2 \mu \mathrm{g}$ each) were made at 5-day intervals, starting from the day of axotomy, in the two groups treated with CNTF.

\section{Visualization of Regenerating RGCs}

The animals were allowed to survive for 30 days in the intracranial model and 20 days in the intraorbital model. To retrogradely label regenerating RGCs, a piece of Gelfoam soaked with 6\% Fluoro-Gold (FG) was applied to the freshly cut distal end of the PN grafts (PN graft paradigms). Animals were given 2 days for retrograde transport of the dye and subsequent labeling of the regenerating RGCs. Animals were then euthanized with an overdose of Sagatal and perfused with $4 \%$ paraformaldehyde. In rats (ON crush experiments), a new transection was made on the crushed ON distal (2 mm) to the crush site, and one or two 4DiI-10Asp (DiAsp) crystals were placed at the newly transected site. In order to limit the possible diffusion of the dye, animals were allowed to survive only another $18 \mathrm{~h}$, and the left retinas were then removed and postfixed in the same fixative for $1 \mathrm{~h}$. They were flat-mounted with $30 \%$ glycerin and examined under fluorescent microscope.

\section{Statistical Analysis}

For statistical analysis of the results, data in each experiment were analyzed using one-way analysis of vari-

Table 1. Average Numbers of Regenerating RGCs with Standard Deviation (SD) in Hamsters with Intraorbital ON Transection and Transplantation of a PN Graft onto ON Stump

\begin{tabular}{lccc}
\hline & No. animals & Mean & SD \\
\hline HRP cells & 3 & 4007 & 1192 \\
IN-1 cells & 3 & 4242 & 1153 \\
\hline
\end{tabular}




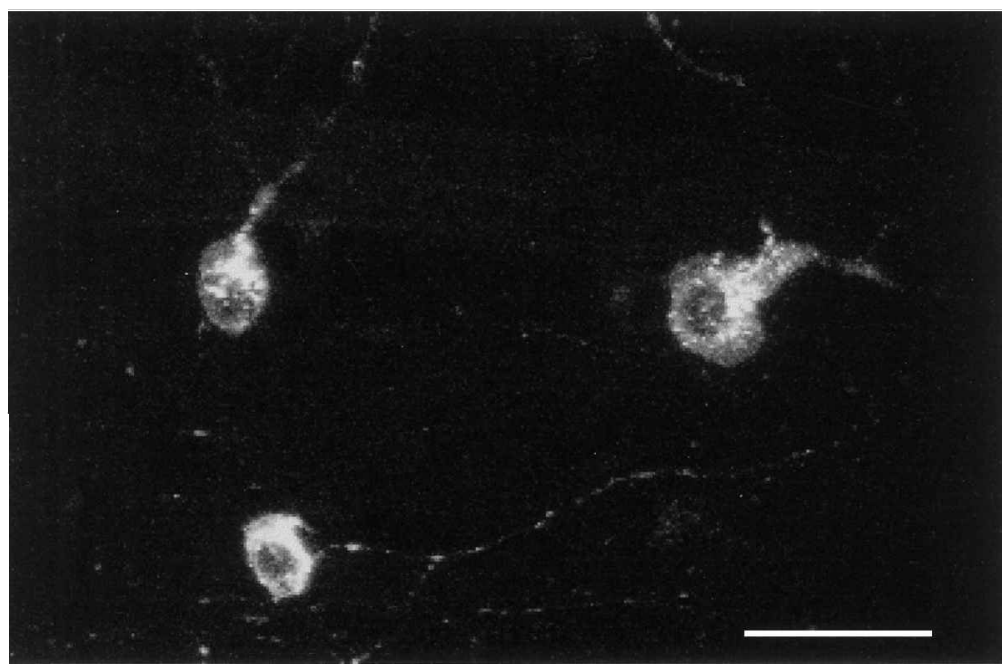

FIG. 2. A representative fluorescence photomicrograph of FG-labeled regenerating RGCs in a retinal wholemount treated with CNTF in distal ON axotomy model. Three regenerating RGCs are seen in this field. Bar $=40 \mu \mathrm{m}$.

ance (ANOVA) followed by Bonferroni tests for intragroup comparisons (Cui et al., 1999, 2003). In the intraorbital PN graft experiment in which only two groups were used, Student $t$ test was used for comparison.

\section{RESULTS}

The eyes with multiple intravitreal injections showed no obvious infections. The intraorbital ON axotomy pro- cedure did not cause severe bleeding. A representative fluorescence photomicrograph of FG-labeled regenerating RGCs in a retinal wholemount treated with CNTF in the distal ON axotomy model is shown in Figure 2.

\section{Intracranial PN Graft Experiments}

The ability of RGCs to regenerate distally axotomized axons in this study was poor. The average number of regenerating RGCs in animals implanted with HRP cells was 1.8 retina (Fig. 3 ). This value is not significantly
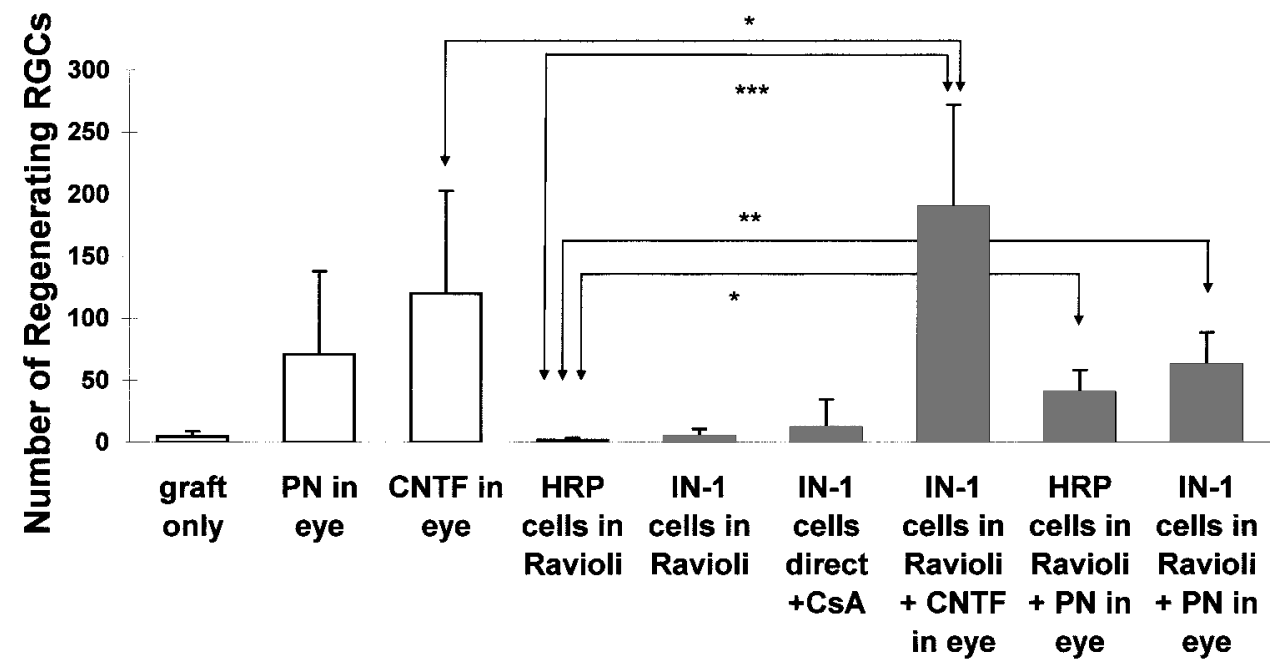

FIG. 3. Experimental results (average numbers of regenerating RGCs and standard deviation) obtained from intracranial ON axotomy plus PN graft model. Data for the empty bars had been published elsewhere (Cui et al., 1999) and were put here for relevant comparisons. A synergistic effect of IN-1 and CNTF was observed. Statistical significant levels were indicated by $* p<$ $0.05, * * p<0.01$, or $* * * p<0.001$. 
different from our previous result in PN graft-only animals with the same experimental paradigm (mean = 4.7/retina, Cui et al., 1999; $p>0.05$, Bonferroni test). Application of IN-1 cells in Ravioli or directly in Gelfoam plus daily i.p. injections of immunosuppressant CsA failed to increase the number of regenerating RGCs. The numbers of regenerating RGCs in this paradigm were 4.7/retina and 11.8/retina, respectively (Fig. 3). Both are not significantly different from the HRP cell control value ( $p>0.05$, Bonferroni test).

When IN-1 cells were applied in Ravioli in conjunction with intravitreal injections of CNTF $(1 \mu \mathrm{g} \times 5)$, the number of regenerating RGCs was increased to 190/retina (Fig. 3). This value is significantly higher than the HRP cell control value $(p<0.001$, Bonferroni test; Fig. 3). Compared with our previous CNTF application-alone group of the same dosage and paradigm (mean $=120 /$ retina, Cui et al., 1999), this value is also significantly higher ( $p<0.05$, Bonferroni test; Fig. 3). Application of HRP cells with a PN segment in eye yielded a value of 40.2/retina (Fig. 3). This value is significantly different from the HRP cell control at $p<0.05$ (Bonferroni test) level (Fig. 3). When IN-1 cells were applied together with a PN segment in the eye, the number of regenerating RGCs further increased to 63/retina (Fig. $3)$. While these two values from PN-treated eyes are not significantly different from each other, the latter value is higher than the HRP control at an even higher level of significance $(p<0.01$, Bonferroni test). These results also indicate a synergistic effect of IN-1 and neurotrophic factors released from the PN. In summary, treatment with IN-1 cells alone failed to increase axon regeneration of distally injured RGCs but it acted synergistically with intravitreal application of appropriate neurotrophic factor to further increase the number of RGCs regenerating axons into PN grafts.

\section{Intraorbital PN Graft Experiments}

The capability of RGCs to regenerate is closely correlated with the distance of the axonal injury site from the cell bodies; in other words, the closer the injury site, the higher the potential that the RGCs are able to regrow their processes (You et al., 2000). Consistent with this observation, the number of regenerating RGCs in the proximal ON injury model was much higher than that in the distal ON injury model. The average number of regenerating RGCs in intraorbitally transected animals treated with HRP cells was 4007/retina (Table 1). Treatment with IN-1 cells alone also failed to significantly increase the number of regenerating RGCs in this model ( $p>0.05$, Student $t$ test) and yielded a mean value of only 4242/retina (Table 1).

\section{Intraorbital ON Crush Experiments}

Considering that the injured RGC axons may not retract a significant distance into the proximal stump of the transected ON, the presence of inhibitory molecules in the part of the ON stump through which regenerating axons have to negotiate and extend into the PN grafts may be low in the PN graft paradigms, and thus the effect of IN-1 treatment would not be easily detected. To maximize the effect of IN-1 treatment, an ON crush model was used to determine if IN-1 treatment would promote the regeneration of injured RGC axons into the distal part of the ON, a CNS environment known to contain high amount of inhibitory molecules produced by the oligodendrocytes.

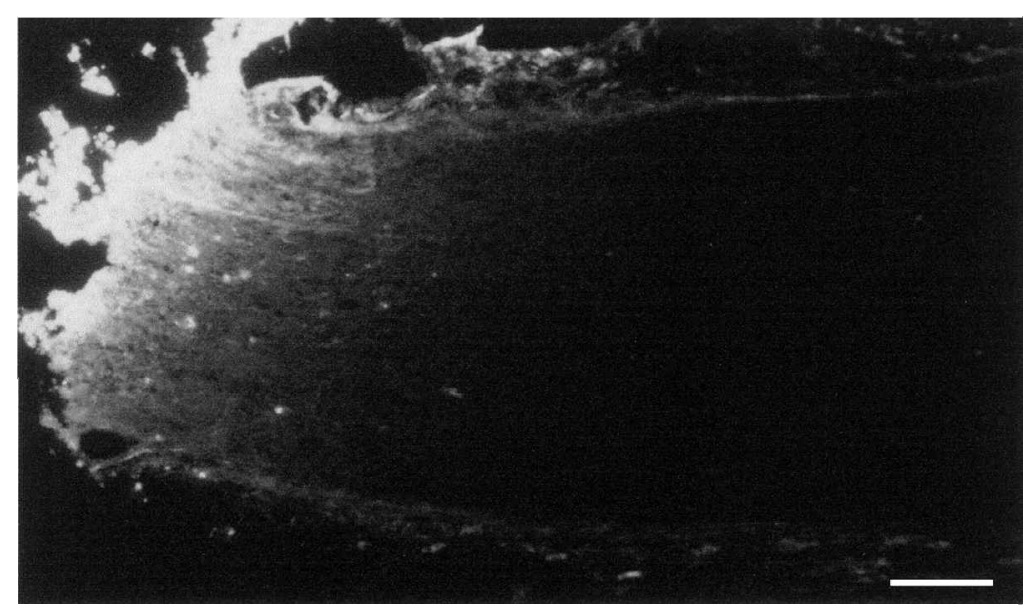

FIG. 4. Fluorescent image of longitudinal section of ON showing the limited diffusion of the fluorescent dye 4Di-10Asp at the tip. Bar $=100 \mu \mathrm{m}$. 
Examination of cryosectioned ON after this short period of labeling revealed limited diffusion of the dye, thus avoiding dye contamination at the crush site and labeling of RGCs by diffusion (Fig. 4). In the control animals with ON crush that received intravitreal injections of saline, the number of RGCs that regenerated their axons for at least $2 \mathrm{~mm}$ into the distal part of the crushed ON was low, an average of 7.5/retina ( $n=6$; Fig. 5). Intravitreal injections of CNTF alone substantially increased the number of regenerating RGCs in this group (mean $=114.9 /$ retina, $n=7$; Fig. 5). Although there was nearly a 15 -fold increase, the increase failed to reach a significant level ( $p>0.05$, Bonferroni test), owing to the high variation in this CNTF treatment group (ranging from 3 to 221/retina, SD = 96; Fig. 5). However, when the two extremely low values ( 3 and 11), suggestive of poor intravitreal CNTF injections, were removed from the data analysis, the average number of regenerating RGCs in CNTF-treated group became significantly higher ( $p<0.05$, Bonferroni test) than the saline control. Note that previous studies have shown that intravitreal injections of CNTF significantly increase the number of regenerating RGCs in a PN graft (Cui et al., 1999).

Treatment with IN-1 hybridoma cells alone achieved a 16-fold increase in the number of regenerating axons in this model (mea $n=114 /$ retina, $n=5$; Fig. 5). Again, owing to the high variation in this group (ranging from 7 to 338/retina, Fig. 5), the increase failed to reach a statistically significant level ( $p>0.05$, Bonferroni test). However, application of IN-1 cells in conjunction with intravitreal injections of CNTF further increased the number of regenerating RGCs. The average number of regenerating RGCs in this condition was 517/retina ( $n=$ 5; Fig. 5). This value is significantly higher than the saline control value ( $p<0.001$, Bonferroni test; Fig. 5). In ad- dition, this value is also significantly higher than both the CNTF-alone treatment group and IN-1 cell-alone treatment group (both $p<0.001$, Bonferroni test; Fig. 5). In summary, treatment with IN-1 cells also acted synergistically with intravitreal application of CNTF to further increase the number of RGCs that regrew axons into the distal part of the ON.

\section{DISCUSSION}

In this study, we implanted IN-1 antibody-secreting hybridoma cells along the pathway of the ON tract using various approaches, such as applying the cells intracranially and/or intraorbitally, in Ravioli or directly with immunosuppressant CsA injection, in intracranial or intraorbital injury models, and with or without intravitreal injection of CNTF. IN-1 hybridoma cell treatment alone failed to significantly enhance RGC axon regeneration into a PN graft in both proximal and distal ON axotomy models or into the distal part of crushed ON. However, IN-1 treatment was found to act synergistically with intravitreal application of CNTF or a PN segment to significantly promote the number of regenerating RGC axons. This is consistent with a previous report in which IN-1 acted synergistically with brain-derived neurotrophic factor (BDNF) to further enhance the regrowth of intracranially crushed RGC axons into the distal side of the ON in developing rats (Weibel et al., 1994) or with NT-3 to further promote the sprouting of corticospinal tract after injury (Schnell et al., 1994).

Neurotrophins have been widely shown to enhance axon regeneration in the CNS. Importantly, a recent study showed that prior exposure of neurons to neurotrophins made them insensitive to the inhibitory effect of myelin

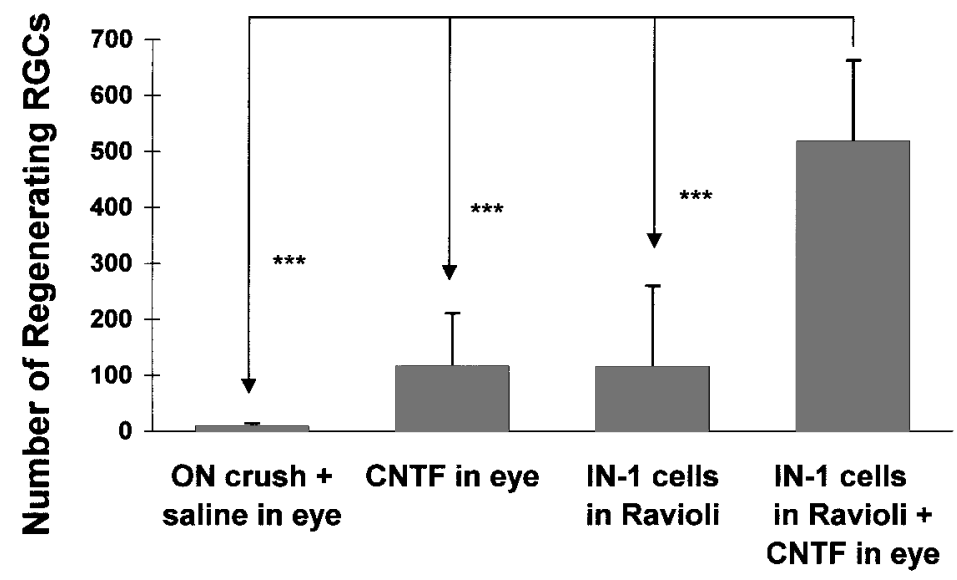

FIG. 5. Experimental results (average numbers of regenerating RGCs and standard deviation) obtained from the intraorbital ON crush model. Statistical significant levels are indicated by $* * * p<0.001$. 
substrates or MAG (Cai et al., 1999). It is known that different neuronal populations have different specificities in response to neurotrophic factors. In rodent visual systems, we found that CNTF, but not BDNF, NT-4/5, NT3 , NGF, or bFGF, promoted RGC axon regeneration into a PN graft (Cui et al., 1999; 2003), even though BDNF and NT-4/5 enhanced RGC survival (Mey and Thanos, 1993; Cui et al., 2003). Although we failed to obtain significantly higher number of RGCs regrowing axons into the distal part of the ON after CNTF treatment, owing to the high level of variation, CNTF may also act on RGCs to overcome inhibitory molecules in a similar fashion as we recently observed significant increase in growthassociated protein-43 (GAP-43)-positive axons in the ON of CNTF-treated rats (S.W. You et al., unpublished observations). IN-1 antibody treatment has recently been reported to upregulate the expression of BDNF, GAP-43, and transcription factors STATs (Bareyre et al., 2002), whose signal pathways may contribute to the enhanced axonal regeneration. The observed synergistic effect of IN-1 and CNTF in this study may be a result of IN-1's blockade of Nogo and upregulation of axon regeneration signaling and CNTF's ability to overcome of the inhibitory effect of other inhibitors such as myelin substrates or MAG.

Although IN-1 promoted axonal regeneration and improved functional recovery under various conditions in at least some parts of the CNS (Thallmair et al., 1998; Z'Graggen et al., 1998; Merkler et al., 2001), blockade of Nogo alone caused only a small number of axons to regrow. This is not surprising as blocking Nogo alone will still allow other inhibitory molecules such as MAG and OMgp to exert inhibitory effects, or scar tissue may form a physical barrier for axons to pass. In addition, the identification of differential Nogo receptor distributions in different neurons and at different developmental ages (Fournier et al., 2001) may explain the lack of action of IN-1 antibodies in certain parts of the CNS (Oudega et al., 2000).

A breakthrough was made recently in our understanding of signaling transduction of these inhibitory molecules. Nogo-A, MAG, and OMgp all act through the same Nogo receptor, forming a receptor complex with p75 to exert their inhibitory effects (Domeniconi et al., 2002; Liu et al., 2002; Wang et al., 2002a,b; Wong et al., 2002). However, a peptide that disrupts the interactions of Nogo receptor with its ligands has been generated and shown to promote robust sprouting of uninjured spinal cord tract fibers, but only limited regeneration of fibers that are damaged (GrandPre et al., 2002). These results further confirm that, apart from Nogo-A, MAG, and OMgp, other inhibitory factors such as amino-Nogo, proteoglycan, tenascin, and scar tissue also play an important part in impeding axon regrowth (Gates et al., 1996; Fawcett, 1997; David and Lacroix, 2003).

In the intraorbital PN graft model, injured axons might not retract a significant distance into the ON stump, and thus the oligodendrocytes and myelin-associated inhibitory molecules through which regenerating RGCs have to negotiate would be present only in a very small portion (retraction distance) of the ON stump and at a low level in the PN grafts. This low level of Nogo molecules may not render them as a dominant inhibitory factor, thus leading to the lack of effect of IN-1 treatment in these conditions.

The less predominant role of oligodendrocyte- and myelin-associated inhibitory molecules in axon regrowth inhibition has been documented under various conditions. Extensive axon regeneration has been seen in both normal and degenerating white matter tracts in the presence of inhibitory molecules; however, regenerating axons were stopped at the glial scar formation site in those studies (Davies et al., 1997, 1999). The role of chondroitin sulfate-proteoglycans as the main inhibitory molecules in scar tissue (Davies et al., 1999) and the subsequent degradation of these molecules leading to enhanced axon regeneration in spinal cord (Moon et al., 2001) have recently been documented.

Recently, intrinsic axon regrowth capability has been enhanced by cellular elevation of cAMP (Cai et al., 1999; Qiu et al., 2002; Neumann et al., 2002). We also showed that CNTF and cAMP elevation acted in concert to promote RGC axon regeneration (Cui et al., 2003). Thus available information suggests that there may not be a single explanation for the failure of CNS axon regeneration, and any attempt to tackle the problem from a single aspect seems to fail. Combined experimental approaches, including neutralization of inhibitory molecules (IN-1 or Nogo receptor blocker), blockade of inhibitory signaling pathways (Rho pathway inhibitor), supplementation of appropriate neurotrophic factors (NT-3 or CNTF), provision of an environment suitable for axon regeneration (PN graft or Schwann cell/olfactory ensheathing glia transplantation), prevention of scar tissue formation (Chondroitinase $\mathrm{ABC}$ ), and elevation of intrinsic regrowth capability (cAMP elevation) will be necessary in any attempt to circumvent this devastating condition (Cheng et al., 1996; Li et al., 1996; Lehmann et al., 1999; Moon et al., 2001; GrandPre et al., 2002; Qiu et al., 2002; Neumann et al., 2002; Cui et al., 2003).

\section{ACKNOWLEDGMENTS}

We thank Professor M.E. Schwab for supplying the HRP and IN-1 hybridoma cells and Regeneron Pharma- 
ceuticals and Regeneron/Amgen Partners for the CNTF. We also thank Phillis Kau and Bing Hu for the initial expansion of the hybridoma cells. This study was supported by research grants from the University of Hong Kong, the Research Grant Council of Hong Kong, the Croucher Foundation of Hong Kong, and Shantou University Medical College.

\section{REFERENCES}

BÄHR, M., and SCHWAB, M.E. (1996). Antibody that neutralizes myelin-associated inhibitors of axon growth does not interfere with recognition of target-specific guidance information by rat retinal axons. J. Neurobiol. 30, 281-292.

BAREYRE, F.M., HAUDENSCHILD, B., and SCHWAB, M.E. (2002). Long-lasting sprouting and gene expression changes induced by the monoclonal antibody IN-1 in the adult spinal cord. J. Neurosci. 22, 7097-7110.

BREGMAN, B.S., KUNKEL-BAGDEN, E., SCHNELL, L., et al. (1995). Recovery from spinal cord injury mediated by antibodies to neurite growth inhibitors. Nature 378, 498-501.

CAI, D., SHEN, Y., DE BELLARD, M., et al. (1999). Prior exposure to neurotrophins blocks inhibition of axonal regeneration by MAG and myelin via a cAMP-dependent mechanism. Neuron 22, 89-101.

CARONI, P., and SCHWAB, M.E. (1988). Two membrane protein fractions from rat central myelin with inhibitory properties for neurite growth and fibroblast spreading. J. Cell Biol. 106, 1281-1288.

CHEN, M.S., HUBER, A.B., VAN DER HAAR, M.E., et al. (2000). Nogo-A is a myelin-associated neurite outgrowth inhibitor and an antigen for monoclonal antibody IN-1. Nature 403, 434-439.

CHENG, H., CAO, Y., and OLSON, L. (1996). Spinal cord repair in adult paraplegic rats: partial restoration of hind limb function. Science 273, 510-513.

CUI, Q., LU, Q., SO, K.-F., et al. (1999). CNTF, not other trophic factors, promotes axonal regeneration of axotomized retinal ganglion cells in adult hamsters Invest. Ophthalmol. Vis. Sci. 40, 760-766.

CUI, Q., and HARVEY, A.R. (2000). CNTF promotes the regrowth of retinal ganglion cell axons into murine peripheral nerve grafts. Neuroreport 11, 3999-4002.

CUI, Q., YIP, H.K., ZHAO, R.C., et al. (2003). Intraocular elevation of cyclic AMP potentiates ciliary neurotrophic factor-induced regeneration of adult rat retinal ganglion cell axons. Mol. Cell. Neurosci. 22, 49-61.

DAVID, S., and LACROIX, S. (2003). Molecular approaches to spinal cord repair. Annu. Rev. Neurosci. 26, 411-440.
DAVIES, S.J.A., FITCH, M.T., MEMBERG, S.P., et al. (1997). Regeneration of adult axons in white matter tracts of the central nervous system. Nature 390, 680-684.

DAVIES, S.J.A., GOUCHER, D.R., DOLLER, C., et al. (1999). Robust regeneration of adult sensory axons in degenerating white matter of the adult rat spinal cord. J. Neurosci. 19, 5810-5822.

DOMENICONI, M., CAO, Z., SPENCER, T., et al. (2002). Myelin-associatedglycoproteininteracts with the Nogo66 receptor to inhibit neurite outgrowth. Neuron 35, 283-290.

FAWCETT, J.W. (1997). Astrocytic and neuronal factors affecting axon regenerationin the damaged central nervous system. Cell Tissue Res. 290, 371-377.

FOURNIER, A.E., GRANDPRE, T., and STRITTMATTER, S.M. (2001). Identification of a receptor mediating Nogo-66 inhibition of axonal regeneration. Nature 409, 341-343.

GATES, M.A., FILLMORE, H., and STEINDLER, D.A. (1996). Chondroitin sulfate proteoglycan and tenascin in the wounded adult mouse neostriatum in vitro: dopamine neuron attachment and process outgrowth. J. Neurosci. 16, 8005-8018.

GRANDPRE, T., NAKAMURA, F., VARTANIAN, T., et al. (2000). Identification of the Nogo inhibitor of axon regeneration as a Reticulon protein. Nature 403, 439-444.

GRANDPRE, T., LI, S., and STRITTMATTER, S.M. (2002). Nogo-66 receptor antagonist peptide promotes axonal regeneration. Nature 417, 547-551.

HUNT, D., MASON, M.R.J., CAMPBELL, G., et al. (2002). Nogo receptor mRNA expression in intact and regenerating CNS neurons. Mol. Cell. Neurosci. 20, 537-552.

KOTTIS, V., THIBAULT, P., MIKOL, D., et al. (2002). Oligodendrocyte-myelin glycoprotein (OMgp) is an inhibitor of neurite outgrowth. J. Neurochem. 82, 1566-1569.

LAU, K.C., SO, K.-F., and TAY, D. (1994). Intravitreal transplantation of a segment of peripheral nerve enhances axonal regeneration of retinal ganglion cells following distal axotomy. Exp. Neurol. 128, 211-215.

LEHMANN, M., FOURNIER, A., SELLES-NAVARRO, I., et al. (1999). Inactivation of Rho signaling pathway promotes CNS axon regeneration. J. Neurosci. 19, 7537-7547.

LI, Y., FIELD, P.M., and RAISMAN, G. (1997). Repair of adult rat corticospinal tract by transplants of olfactory ensheathing cells. Science 277, 2000-2002.

LIU, B.P., FOURNIER, A., GRANDPRE, T., et al. (2002). Myelin-associated glycoprotein as a functional ligand for the Nogo-66 receptor. Science 297, 1190-1193.

MERKLER, D., METZ, G.A.S., RAINETEAU, O., et al. (2001). Locomotor recovery in spinal cord-injured rats treated with an antibody neutralizing the myelin-associated neurite growth inhibitor Nogo-A. J. Neurosci. 21, 3665-3673. 
MCKERRACHER, L., DAVID, S., JACKSON, D.L., et al. (1994). Identification of myelin-associated glycoprotein as a major myelin-derived inhibitor of neurite growth. Neuron 13, 805-811.

MEY, J., and THANOS, S. (1993). Intravitreal injections of neurotrophic factors support the survival of axotomised retinal ganglion cells in adult rats in vivo. Brain Res. 602, 304-317.

MOON, L.D.F., ASHER, R.A., RHODES, K.E., et al. (2001). Regeneration of CNS axons back to their target following treatment of adult rat brain with chondroitinase ABC. Nat. Neurosci. 4, 465-466.

MUKHOPADHYAY, G., DOHERTY, P., WALSH, F.S., et al. (1994). A novel role of myelin-associated glycoprotein as an inhibitor of axonal regeneration. Neuron 13, 757-767.

NEUMANN, S., BRADKE, F., TESSIER-LAVIGNE, M., et al. (2002). Regeneration of sensory axons within the injured spinal cord induced by intraganglionicc AMP elevation. Neuron 34, 885-893.

OUDEGA, M., ROSANO, C., SADI, D., et al. (2000). Neutralizing antibodies against neurite growth inhibitor NI$35 / 250$ do not promote regeneration of sensory axons in the adult rat spinal cord. Neuroscience 100, 873-883.

QIU, J., CAI, D., DAI, H., et al. (2002). Spinal axon regeneration induced by elevation of cyclic AMP. Neuron 34, 895-903.

RICHARDSON, P.M., McGUINNESS, U.M., and AGUAYO, A.J. (1980). Axons from CNS neurons regenerate into PNS grafts. Nature 284, 264-265.

SCHNELL, L., SCHNEIDER, R., KOLBECK, R., et al. (1994). Neurotrophin-3 enhances sprouting of corticospinal tract during development and after adult spinal cord lesion. Nature 367, 170-173.

SO, K.-F., and AGUAYO, A.J. (1985). Lengthy regrowth of cut axons from ganglion cells after peripheral nerve transplantation into the retina of adult rats. Brain Res. 328, 349-354.

THALLMAIR, M., METZ, G.A.S., Z'GRAGGEN, W.J., et al. (1998). Neurite growth inhibitors restrict plasticity and func- tional recovery following corticospinal tract lesions. Nat. Neurosci. 1, 124-131.

WANG, K.C., KOPRIVICA, V., KIM, J.A., et al. (2002a). Oligodendrocyte-myelin glycoproteim is a Nogo receptor ligand that inhibits neurite outgrowth. Nature 417, 941-944.

WANG, K.C., KIM, J.A., SIVASANKARAN, R., et al. (2002b). p75 interacts with the Nogo receptor as a coreceptor for Nogo, MAG and OMgp. Nature 420, 74-78.

WEIBLE, D., CADELLI, D., and SCHWAB, M.E. (1994). Regeneration of lesioned rat optic nerve fibers is improved after neutralization of myelin-associated neurite growth inhibitors. Brain Res. 642, 259-266.

WONG, S.T., HENLEY, J.R., KANNING, K.C., et al. (2002). A p75 NTR and Nogo receptor complex mediates repulsive signaling by myelin-associate glycoprotein. Nat. Neurosci.5, 1302-1308.

YIN, Y., CUI, Q., LI, Y., et al. (2003). Macrophage-derived factors stimulate optic nerve regeneration. J. Neurosci. 23, 2284-2293.

YOU, S.W., SO, K.-F., and YIP, H.K. (2000). Axonal regeneration of retinal ganglion cells depending on the distance of axotomy in adult hamsters. Invest. Ophthalmol. Vis. Sci. 41, 3165-70.

Z'GRAGGEN, W.J., METZ, G.A., KARTJE, G.L., et al. (1998). Functional recovery and enhanced corticofugal plasticity after unilateral pyramidal tract lesion and blockade of myelin-associated neurite growth inhibitors in adult rats. J. Neurosci. 18, 4744-4757.
Address reprint requests to:
Henry K. Yip, Ph.D.
Department of Anatomy
Faculty of Medicine
The University of Hong Kong
Hong Kong
E-mail: hkfyip@hku.hk 